\title{
Hepatitis B and hepatitis C prevalence in HIV positive pregnant women Gilbert Siame*
}

Address: Kitwe Central Hospital, Kitwe, Zambia

* Corresponding author

from 2006 International Meeting of The Institute of Human Virology

Baltimore, USA. 17-2I November, 2006

Published: 21 December 2006

Retrovirology 2006, 3(Suppl I):P60 doi:I0.I I86/1742-4690-3-SI-P60

(C) 2006 Siame; licensee BioMed Central Ltd.

\section{Background}

Few studies, if any, of hepatitis B (HBV), hepatitis C (HCV) and HIV co-infections in pregnant women in Zambia have been undertaken. HBV, HCV and HIV share at least one common route of infection: blood to blood contact through various transmission modalities.

\section{Objective}

In this study, the researcher attempted to evaluate the prevalence of HBV and HCV co-infections among HIV positive pregnant women.

\section{Method}

Ninety-seven HIV positive pregnant women (not yet on HAART) admitted to mostly labor ward were clinically examined and had their case files reviewed. They were also on PMTCT program for HIV. HBV surface antigens and anti-HCV antibodies were checked using ELISA. Information concerning their HIV status was obtained from the case files and antenatal cards.

\section{Results}

- HCV antibody seroprevalence was 4.1\%(4/97), while the prevalence of HBV was found to be $9.3 \%(9 /$ 97).86.6\%(84/97) of the cases had only HIV infection

- Those with HBV/HCV co-infection tended to be older (age range 26-37 years), and all were black women three quarters of whom had poor socio-economic status

- $38.5 \%$ of those with co-infection reported having had a sexually transmitted infection (STI)
- Only $9.3 \%$ of all the cases had done their CD4 counts. Those with HBV had an average CD4 of 350 cells/ml; HCV with 417 cells/ml, and those without co-infection with 271 cells/ml.

\section{Conclusion}

- HBV/HCV co-infection in HIV is common (usually under-diagnosed in this country)

- Co-infection with HBV/HCV/HIV seems to be associated with older age

- Difficult to assess if co-infection with $\mathrm{HBV} / \mathrm{HCV}$ has impact on CD4 count because most subjects cannot afford expensive CD4 measurements in this country

- HBV/HCV/HIV co-infection may pose serious challenges to success of HAART in this country with limited resources

- A more comprehensive study is needed to elucidate the full extent of this problem in the general population 